\title{
Association of TNF-a (rs361525 and rs1800629) with susceptibility to cervical intraepithelial lesion and cervical carcinoma in women from Republic of North Macedonia
}

\author{
Sotirija Duvlis $^{1,2}$ (D) | Drage Dabeski ${ }^{3}$ | Aleksandar Cvetkovski $^{2}$ \\ Kristina Mladenovska ${ }^{4}$ (i) | Dijana Plaseska-Karanfilska ${ }^{5}$
}

\author{
${ }^{1}$ Department of Virology and Molecular \\ Diagnostics, Institute of Public Health of \\ North Macedonia, Skopje, Republic of North \\ Macedonia \\ ${ }^{2}$ Faculty of Medical Sciences, Stip, Republic \\ of North Macedonia \\ ${ }^{3}$ University Clinic for Gynecology and \\ Obstetrics, University "Ss. Cyril and \\ Methodius", Skopje, Republic of North \\ Macedonia \\ ${ }^{4}$ Faculty of Pharmacy, University "Ss. Cyril \\ and Methodius", Skopje, Republic of North \\ Macedonia \\ ${ }^{5}$ Research Centre for Genetic Engineering \\ and Biotechnology, Academy of Sciences \\ and Arts, Skopje, Republic of North \\ Macedonia
}

\section{Correspondence}

Sotirija Duvlis, Laboratory for virology and molecular diagnostics, Institute of Public health of Republic of North Macedonia, 50 Division 6, Skopje, Republic of North Macedonia; Faculty of Medical Sciences, "Goce Delchev" University, St. Krste Misirkov 10-A, 2000, Stip, Republic of North Macedonia.

Emails: sotirijaduvlis@yahoo.com; sotirija. duvlis@ugd.edu.mk

\begin{abstract}
Cervical cancer ( $\mathrm{CC}$ ) is one of the most common malign diseases in women associated with human papillomavirus (HPV). The virus is an initiating factor, but not sufficient for the development of cervical intraepithelial lesions (CIN) and CCa. The disease might be a result of the influence of host's genetic factors and polymorphisms in inflammatory-related genes that modify the immune response to HPV and attribute to cancer susceptibility. We carried out a study to determine the association between TNF-a-238G/A and TNF-a-308 G/T polymorphisms with HPV-positive $\mathrm{CIN}$ and $\mathrm{CCa}$ in women living in the Republic of North Macedonia. Using multiplex $\mathrm{SNaPshot}$ analysis for single nucleotide polymorphisms (SNPs), we analysed the genotype and allele distributions of TNF-a-238G/A and TNF-a-308 G/T in 134 cases (HPV-positive and histologically confirmed CIN and CCa) and in 113 controls (cytological and HPV-negative women). For further analysis, the case group was stratified in three subgroups (all cases: $\mathrm{CINs}+\mathrm{CCa}$ - group; CIN2+-group and CIN1- group). Data analysed using the odds ratio (OR) and chi-square test showed the frequency of $\mathrm{AA}$ genotypes and $\mathrm{A}$ alleles are not significantly higher in cases compared to the controls for both SNPs: AA of TNF-a-238 (0.7\% versus $0 \%)$ and TNF-a-308 (1.5\% versus $0.9 \%$ ) as well as A allelic frequency (3.0\% versus $1.7 \%$ ) and (13.1\% versus 10.6$)$, respectively. The comparison of the case's subgroups with the control group did not show a statistically significant difference. Compared to controls, TNF-a-238G/A and TNF-a-308 G/T are not associated with the risk of HPV associated CIN or CCa in the studied women.
\end{abstract}

\section{KEYWORDS}

cervical cancer, cervical intraepithelial lesions, host's susceptibility, human papillomavirus, tumour necrosis factor-alpha (TNF- $\alpha$ ) polymorphisms

\section{1 | INTRODUCTION}

Although human papillomavirus (HPV) is the most important aetiological agent of initiation of cervical intraepithelial abnormalities, the majority of infections resolve spontaneously and do not confer progression to disease. Studies have reported an association of single nucleotide polymorphisms (SNPs) within cytokine genes with cell clearance from HPV viral infection (Fong, Siddiqui, \& Mark, 1994) as well as susceptibility to a higher risk of human malignant tumours (Eskdale et al., 1998; Nunobiki et al., 2011; Ueda 
et al., 2003). Cytokines molecules are involved in the fighting of an organism against viral infections and could influence the HPV persistence and cervical intraepithelial neoplasia (CIN) progression changing the immune response to HPV and modifying the risk for CCa. Tumour necrotizing factor (TNF-a) is an important pro-inflammatory cytokine involved in host immune defence from different pathogens including the HPV infection, its beneficial role, but it could be also harmful when its systemic higher production lead to autoimmune or malign diseases (Hajeer \& Hutchinson, 2001). Two SNPs in this gene (rs361525 and rs1800629) could influence the CCa susceptibility based on finding that they can modulate TNF- $a$ expression: rs1800629 A allele tends increasing and rs361525 A allele lowering the TNF-a expression (Fong et al., 1994; Kroeger, Carville, \& Abraham, 1997; Wilson, Symons, McDowell, McDevitt, $\&$ Duff, 1997).

A number of studies investigated the association of these polymorphisms with different cancers, including cervical cancer (Li, Liu, Liu, \& Lu, 2018; Roszak, Misztal, Sowinska, \& Jagodzinski, 2015), and their implication in control of HPV infection and inhibition of E6/ E7 transcription in keratinocytes infected with HPV 16 and HPV 18 (Kyo et al., 1994; Soto, Das, Lengert, Finzer, \& zur Hausen, \& Rosl, 1999) as well. So far, many such studies reported contradictory or ambiguous results. The exact mechanism that could affect susceptibility to $\mathrm{CIN}$ and $\mathrm{CCa}$ is still unknown. It could be possible that different mechanisms influence this process.

We conducted a case-control study to find out whether rs361525 and rs1800629 gene promoter polymorphisms are associated with HPV-positive CIN and CCa. Referring to the previous finding revealing that HPV persistent infection is the main risk for cervical lesion development; in this study, we included only HPVpositive and histologically confirmed CINs and CCa. To the best of our knowledge, still, no report is available addressing the association of these SNPs in the TNF- $\alpha$ promoter with the susceptibility to HPV associated $\mathrm{CIN}$ and $\mathrm{CCa}$ in women living in the Republic of North Macedonia.

\section{MATERIAL AND METHODS}

\section{1 | Study subjects}

The study was performed on 113 healthy controls (HPV and cytological negative women) which underwent routine screening for cervical cancer (HPV testing combined with cervical cytology) and 134 patients (HPV-positive and histological CIN or CCa confirmed women) that were recruited in the Clinic for Gynecology and Obstetrics, Skopje for further examination.

All the samples were collected from the women living in the Republic of North Macedonia. The cytological and/or histological status was confirmed by pathological diagnosis on cervical swabs and surgical specimens, respectively. The cytological diagnosis was done by cytologists using the Bethesda classification system. Histology was performed on specimens collected by a colposcopy-directed biopsy and/or cone specimens collected by loop excision procedure in patients where it was indicated or on surgical specimens. HPV DNA and SNP typing were performed on DNA isolated from cervical swabs, in the Laboratory for Virology and Molecular Diagnostics of the Institute of Public Health of the Republic of North Macedonia (IPHRNM) and the Research Center for Genetic Engineering and Biotechnology (RCGIB), Academy of Sciences and Arts of Republic of North Macedonia (MASA).

Clinical data were collected from the medical records of patients admitted in the Clinic for Gynecology and Obstetrics, Skopje. The average age of the patients ( $40 \mathrm{CIN} 1,57 \mathrm{CIN} 2 / 3,37$ CCa) was 46.38 ( \pm 11.42 years' deviation from the mean). Control cases had a mean age of 46.11 years \pm 9.41 years. Eligible control had no history of HPV and CIN. Written informed consent and a fulfilled questionnaire were obtained from all patients and the control women. All participants were voluntarily involved in this research.

The study protocol was approved by the Ethics Committee of the Institute of Public Health of the Republic of North Macedonia following the tenets of the Helsinki Declaration and national guidelines for medical research.

\section{2 | DNA isolation}

QIAamp DNA Blood Mini Kit was used for DNA extraction from cervical swabs according to the manufacturer's instructions.

\section{3 | HPV testing}

Human papillomavirus testing was performed using HPV4ACE screening, Seeplex, Seegene, Korea. HPV-positive and not genotyped cases were additionally analysed with PCR method based on the amplification of the viral L1 region using MY09/11 consensus degenerate primers (Bernard et al., 1994).

\section{4 | SNP genotyping}

Single nucleotide polymorphisms Genotyping was performed using a multiplex polymerase chain reaction (PCR) followed by singlenucleotide primer extension assay test. The primers that were used in both analyses were designed using the primer design softwarePrimer3Plus (http://www.bioinformatics.nl/cgi-bin/primer3plus/ primer3plus.cgi). Secondary structures and potential primer dimers were predicted using the PriDimerCheck (http://biocompute.bmi. ac.cn/MPprimer/primer_dimer.html). The primers sequences are shown in Table 1. The PCR multiplex reaction was performed in $25 \mu \mathrm{l}$ final volumes, and the mix contained $1 \times$ Reaction Buffer, $200 \mu \mathrm{M}$ of dNTPs, $2 \mathrm{mM}$ of $\mathrm{MgCl}_{2}$, $2 \mathrm{U}$ of AmpliTaq Gold polymerase (Applied Biosystems) and $10 \mathrm{ng}$ of genomic DNA. Cycling conditions were as follows: $10 \mathrm{~min}$ at $95^{\circ} \mathrm{C}$, followed by 35 cycles of $1 \mathrm{~min}$ at $95^{\circ} \mathrm{C}$, 
TAB LE 1 Primers used in multiplex and for single-nucleotide primer extension reaction in detection of rs361525 and rs1800629

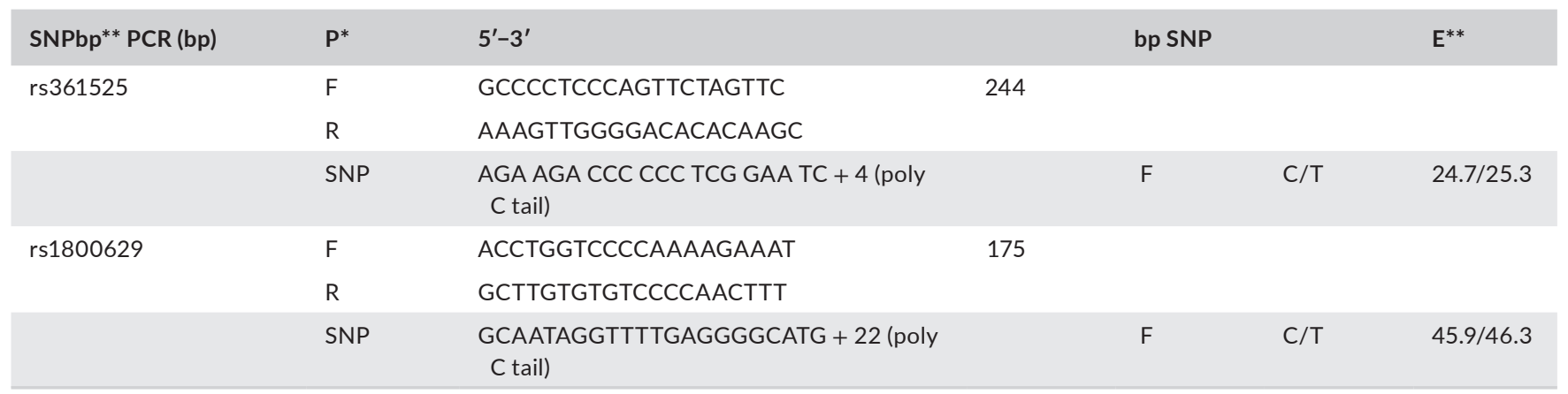

Note: *Primer orientation F (forward), R (reverse).

Abbreviations: bp, base pairs of PCR product; $\mathrm{E}^{* *}$, Electrophorogram position (referent/variant); $\mathrm{P}^{*}$, Primer orientation.

$1 \mathrm{~min}$ and $15 \mathrm{~s}$ at $59^{\circ} \mathrm{C}, 2 \mathrm{~min}$ at $72^{\circ} \mathrm{C}$ and a final extension at $72^{\circ} \mathrm{C}$ for $10 \mathrm{~min}$.

Before the single base extension reaction, an aliquot of $1 \mu \mathrm{l}$ of the PCR product was treated with $0.5 \mu \mathrm{l}$ of ExoSAP-IT (USB Corporation) for $60 \mathrm{~min}$ at $37^{\circ} \mathrm{C}$ to eliminate unincorporated nucleotide triphosphates and excess PCR primers. The enzymes were inactivated at $86^{\circ} \mathrm{C}$ for $20 \mathrm{~min}$. Multiplex single base extension reaction was performed in $5 \mu$ final volume, combining $2 \mu$ l of SNaPshot ready reaction mix (Applied Biosystems), $2 \mu \mathrm{l}$ of the purified PCR product and $1 \mu \mathrm{l}$ of the mutation-specific primer cocktail. The mutation-specific primer primers were $5^{\prime}$ tailed with a poly $C$ sequence to produce extension products with 24 and 44 nucleotides long to allow separation by capillary electrophoresis. The cycling conditions were $10 \mathrm{~s}$ at $96^{\circ} \mathrm{C}, 10 \mathrm{~s}$ at $50^{\circ} \mathrm{C}$ and $30 \mathrm{~s}$ at $60^{\circ} \mathrm{C}$, for 25 cycles. To remove unincorporated ddNTPs, the final products were incubated with $1 \mathrm{U}$ of shrimp alkaline phosphatase (SAP) (USB Corporation) for $1 \mathrm{hr}$ at $37^{\circ} \mathrm{C}$, followed by $15 \mathrm{~min}$ at $85^{\circ} \mathrm{C}$ to inactivate the enzyme. The $1 \mu$ l of the SAP-inactivated single-nucleotide extension reaction was diluted with $12 \mu \mathrm{l} \mathrm{Hi-Di} \mathrm{Formamide} \mathrm{(Life} \mathrm{Technologies)} \mathrm{and} \mathrm{sup-}$ plied with $0.5 \mu$ l GeneScan 120 LIZ Size Standard (Life Technologies). The mixture was denatured at $95^{\circ} \mathrm{C}$ for 5 min and loaded onto an $A B I$ PRISM 3,130 Genetic Analyzer (Life Technologies). Capillary electrophoresis was performed following the manufacturer's instructions. Extension products were visualized and analysed using GeneScan 4.0 (Life Technologies). Initial validation of the method was performed against the DNA sequencing of the amplified regions.

\section{5 | Statistical analysis}

The association between polymorphisms and the stage of cervical lesions was assessed using the Pearson chi-square test and the Fisher exact test, where indicated. A probability level of less than 0.05 was considered as statistically significant. An estimation of odds ratio $(\mathrm{OR})$ and $95 \%$ confidence interval $(\mathrm{Cl})$ for each allele and gene were performed. GG genotype was used as a reference genotype for both

TABLE 2 Clinical and demographic characteristic of study group (age, histological results and HPV type presence)

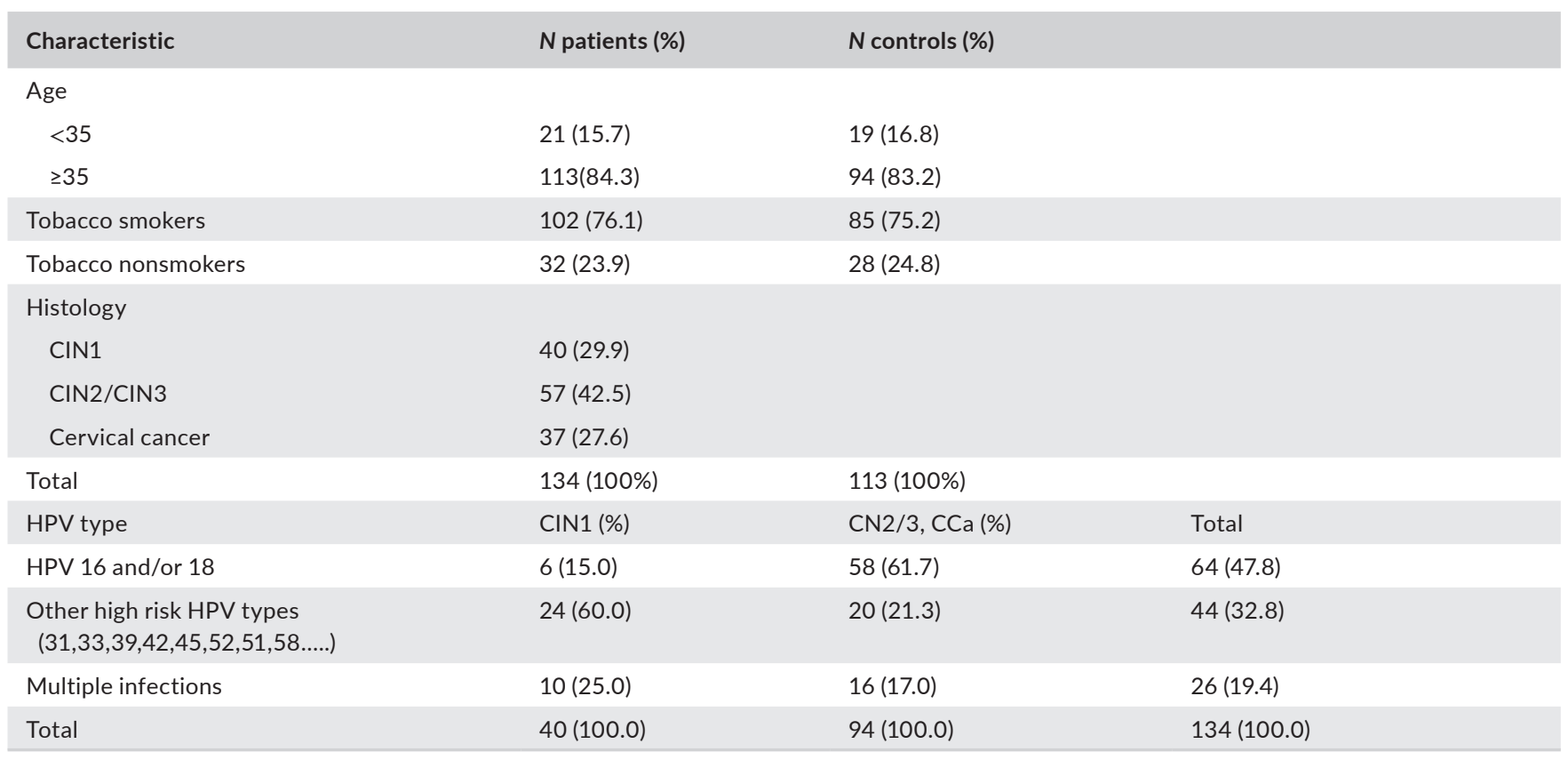


rs361525 and rs1800629. The alleles in the control group were analysed for Hardy-Weinberg equilibrium using a chi-square test with SISA statistics available at http://www.quantitativeskills.com/sisa/ statistics/twoby2.htm. The haplotype analyses were done using SHEsis software (http://www.analysis.bio-x.cn/myAnalysis.php).

\section{3 | RESULTS}

This study was performed on 247 women that were analysed for rs1800629 and rs361525 polymorphisms. The demographic and clinical characteristics of the case and the control group are presented in Table 2. The allelic and genotype frequencies of the SNPs in the cases stratified in three groups and the control group are summarized in Tables 3 and 4 and included the results of the chi-squared tests performed to detect any association between the two SNPs and the development of precancerous lesions or cervical cancer. The large $p$ values varying between 0.1 and 0.5 indicated no statistically significant differences between the case and the control group for both SNPs tested. The alleles in the control group were within Hardy-Weinberg equilibrium.

The lack of association between analysed SNPs and HPV associated cervical lesions cancer and cervical cancers were in addition confirmed by the large $p$ values obtained on genotype-based analysis as well as on the dominant and recessive model analysis.

Both comparisons did not find statistically significant differences between all the case groups and the control group. It should be noted that we could not test the recessive model in case of SNP rs1800629 due to lack of women with AA genotype in the control group.

Regarding HPV type distribution, HPV 16 and HPV 18 were confirmed as more frequent in higher grade precancerous lesions and CCa compared to CIN1 (Pearson's $=26.5, p=0$ ).
The statistical analysis concluded that the analysed polymorphisms cannot be associated with the development of precancerous lesions or cervical cancer with statistical significance. Haplotype analysis also did not show a significant difference between SNPs in the case group (collectively and divided into subgroups) and the control group (Table 5).

\section{4 | DISCUSSION}

Tumour necrosis factor-alpha (TNF- $\alpha$ ) is a potential pro-inflammatory cytokine that plays a critical role in a wide range of inflammatory, autoimmune and malignant diseases (Bazzoni \& Beutler, 1996; Beutler \& Bazzoni, 1998). Its function in the immune response has been implicated in the development of cancer (Dranoff, 2004) mainly through induction of proliferation, invasion and metastasis of tumour cells (Roszak, Misztal, Sowinska, \& Jagodzinski, 2015). A study has confirmed a pivotal role of TNF- $\alpha$ in tumour promotion (Moore, O'Garra, de Waal Malefyt, Vieira, \& Mosmann, 1993). High levels of serum TNF-a were detected in CCa patients with bed prognosis (Chopra, Dinh, \& Hannigan, 1998).

The role of TNF- $\alpha$ in innate immunity and malign pathology is challenging to investigate due to its genetic characteristics that are reflected through regulating its production. TNF-a SNPs 238G/A and 308G/A were most frequently analysed polymorphisms as CCa susceptibility markers.

Our study is based on the hypothesis that A allele at rs361525 allele has a protective effect and the same allele at rs1800629 is associated with the susceptibility to develop cervical cancer (Pan et al., 2012). The results failed to confirm this hypothesis.

However, the results regarding the genotype frequency of AA/ GA at rs361525 and rs1800629 (5.2\% with $24.5 \%$, respectively) in HPV-positive CIN and CCa women in our study are in accordance

TABLE 3 Allele and genotype frequency of rs361525 in cases and controls

\begin{tabular}{|c|c|c|c|c|c|c|c|c|}
\hline rs361525 & G1n (\%) & G2 n (\%) & G3 n (\%) & controls n (\%) & P1 & P2 & P3 & P4 \\
\hline$A$ & $8(3.0)$ & $8(4.2)$ & 0 & $4(1.7)$ & $0.5^{*}$ & $0.15^{*}$ & $0.57^{*}$ & $0.1^{*}$ \\
\hline \multicolumn{9}{|l|}{ Genotype } \\
\hline$A A$ & $1(0.7)$ & $1(1.0)$ & 0 & 0 & $1^{*}$ & $0.4^{*}$ & $1^{*}$ & 1 \\
\hline GG & $127(94.8)$ & $87(92.6)$ & $40(100)$ & $109(96.5)$ & Ref & Ref & Ref & \\
\hline $\begin{array}{l}{ }^{\mathrm{a}} \mathrm{AG} / \mathrm{AA} \text { versus } \\
\mathrm{GG}\end{array}$ & $7(5.2)$ & $7(7.4)$ & 0 & $4(3.5)$ & $0.75^{*}$ & 0.2 & 0.57 & $0.1^{*}$ \\
\hline $\begin{array}{l}{ }^{\mathrm{b}} \mathrm{AA} \text { versus } \mathrm{AG} / \\
\mathrm{GG}\end{array}$ & 133(99.3) & $93(99.0)$ & $40(100)$ & $113(100)$ & $1^{*}$ & 0.45 & 1 & 1 \\
\hline
\end{tabular}

Note: $\mathrm{p} 1$ = G1 (all cases)/controls; p2 = G2 (CIN2/3 + Cca)/controls; p3 = G3 (CIN1)/controls; p4 = G3/G2

${ }^{a}$ Recessive model.

${ }^{\mathrm{b}}$ Dominant model.

${ }^{*} p$ value calculated by Fisher exact test. 
TABLE 4 Allele and genotype frequency of rs1800629 in cases and controls

\begin{tabular}{|c|c|c|c|c|c|c|c|c|}
\hline rs1800629 & G1 n (\%) & G2 n (\%) & G3 n (\%) & controls $n$ (\%) & P1 & P2 & P3 & P4 \\
\hline$A$ & 35 (13.1) & $24(12.8)$ & $11(13.8)$ & $24(10.6)$ & 0.4 & 0.5 & 0.5 & 0.8 \\
\hline \multicolumn{9}{|l|}{ Genotype } \\
\hline AA & $2(1.5)$ & $1(1.1)$ & $1(2.5)$ & $1(0.9)$ & $1^{*}$ & $1^{*}$ & $.4^{*}$ & $.5^{*}$ \\
\hline GG & $101(75.4)$ & $71(75.5)$ & $30(75.0)$ & $90(79.6)$ & Ref & Ref & Ref & Ref \\
\hline AG/AA versus $G^{a}$ & $33(24.6)$ & $23(24.5)$ & $10(25.0)$ & $23(20.4)$ & 0.36 & 0.47 & 0.6 & 1 \\
\hline$A A$ versus $A G / G G^{b}$ & $142(98.5)$ & 93 (98.9) & $39(97.5)$ & $112(99.1)$ & $1^{*}$ & 0.59 & $0.1^{*}$ & 0.5 \\
\hline$n$-total & $134(100)$ & $94(100)$ & $40(100)$ & $113(100)$ & - & - & - & - \\
\hline
\end{tabular}

Note: $\mathrm{p} 1$ = G1 (all cases)/controls; p2 = G2 (CIN2/3 + Cca)/controls; p3 = G3 (CIN1)/controls; p4 = G3/G2

${ }^{\text {a }}$ Recessive model.

${ }^{b}$ Dominant model.

*p value calculated by Fisher exact test.

TAB LE 5 The association between TNF-a haplotypes and CIN/CCa

\begin{tabular}{|c|c|c|c|c|c|c|c|}
\hline rs361525/rs1800629 & Cases(freq) & Control (freq) & Chi2 & FisherP & OR & $95 \% \mathrm{C}$ & \\
\hline $\mathrm{GA}^{*}$ & $23.02(0.122)$ & $24.00(0.106)$ & 0.29 & 0.59 & 1.18 & 0.64 & 2.16 \\
\hline $\mathrm{GG}^{*}$ & $156.98(0.835)$ & $198.00(0.876)$ & 1.14 & 0.28 & 0.74 & 0.42 & 1.28 \\
\hline $\mathrm{AA}$ & $0.98(0.005)$ & $0.00(0.000)$ & & & & & \\
\hline
\end{tabular}

TAB LE 6 Distribution (\%) of rs361525 and rs1800629 genotypes in HPV-positive CIN and CCa women among different population

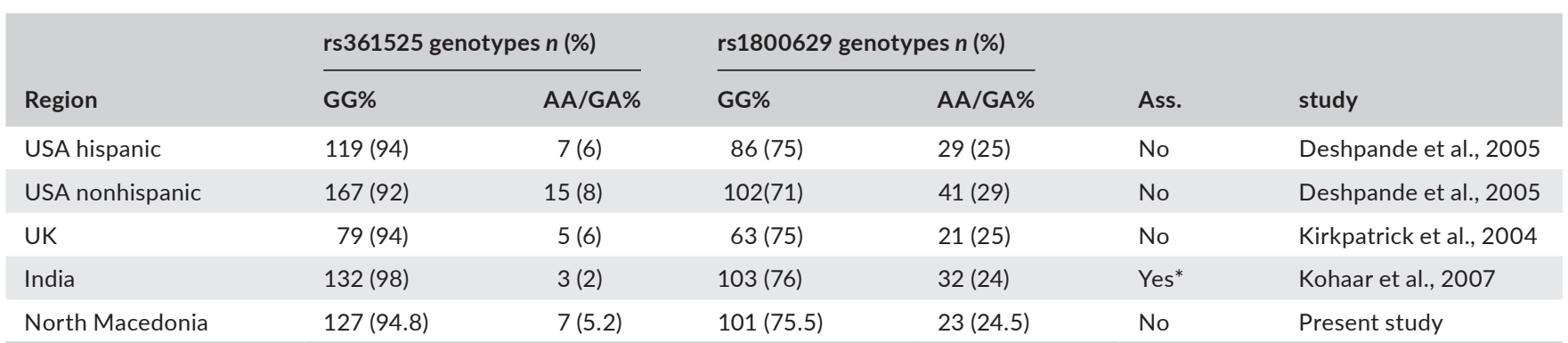

Abbreviations: Ass., association; $h^{*}$, hispanic; $n^{*}$, nonhispanic; Yes*, there is confirmed association only for rs1800629.

with the results obtained in same case group from other different geographical populations such as the USA (Hispanic women: $6 \%$ and 25\%; Nonhispanic: $8 \%$ and 29\%) (Deshpande et al., 2005); UK: 6\% and 25\%; (Kirkpatrick et al., 2004) and India: 2\% and 24\% (Kohaar et al., 2007). A slightly lower frequency of AA/GA for rs361525 may be noted for women in North Macedonia compared to the women in the USA and UK and slightly higher than Indian women. After comparing the rs361525 and rs1800629 genotype frequencies from our study to previously reported frequencies by other authors within the same geographical region (Pavkovic et al., 2017; Trajkov et al., 2009), a small difference is found in rs361525: AA/AG (8.5\%), that may be explained with the larger control group used in the other study that consisted of 310 individuals including male individuals, compared to 113 women controls in this study. The AA/GA genotype frequencies of rs1800629 are found to be comparable (20.8\%) (Pavkovic et al., 2017) (Table 6).

A number of studies conducted in the previous years, analyzing the association of rs361525 and rs1800629 with development of cervical cancer, failed to establish a statistically significant relationship, and the results were inconclusive and contradictory (Calhoun et al., 2002; Deshpande et al., 2005; Duarte et al., 2005; Gostout et al., 2003; Govan, Constant, Hoffman, \& Williamson, 2006; Ivansson, Magnusson, Magnusson, Erlich, \& Gyllensten, 2008; Jang et al., 2001; Kohaar et al., 2007; Singh, Jain, Sachan, \& Mittal, 2009; Stanczuk, Sibanda, Tswana, \& Bergstrom, 2003; Wang, Zhang, Walayat, Chen, \& Wang, 2011; Zhou et al., 2011). The differences in the results may be partially attributed to differences of factor such as sample size, inadequate statistical power 
of the studies, racial and ethnic differences, publication bias or uncorrected multiple hypothesis testing. Some additional factors may also influence the difference in susceptibility to CCa regarding this polymorphism such as contraceptive usage, time of first intercourse, living environment and habits, economic conditions and psychological factors. Future studies should take these additional factors into consideration. The difference in results may also be attributed to gene-gene interactions and the evidence that TNF$\alpha$ is part of the MHC class III cluster. The individual variations in TNF- $\alpha$ production are related to the whole haplotype rather than to the effect of individual TNF- $\alpha$ alleles (Abraham et al., 1993). This finding may suggest future studies should avoid looking into the TNF- $\alpha$ as an isolated gene. Regarding the HPV types distribution, the results are in accordance with many previous studies (Bergeron et al., 1992; Duvlis et al., 2002) but this study cannot clarify the mechanism of HPV type influence on TNF-a SNP genotype association with CIN and CCa.

This study provided valuable data about the allele and genotype frequencies of this variant in women with $\mathrm{CIN}$ and cervical cancer living in Republic of North Macedonia.

\section{5 | CONCLUSION}

According to our knowledge, this study reports the initial TNF- $\alpha$ rs361525 and rs1800629 polymorphisms results in CINs and the cervical cancer women from the Republic of North Macedonia. The genetic testing of these polymorphisms for individual susceptibility to HPV infection and CCa failed to confirm the association between these variants and cervical carcinogenesis in the examined women. To clarify the pathogenesis of HPV induced cervical lesions and cervical cancer, a meta-analysis of different cytokines may be required and the influence of additional factors should be considered.

\section{ACKNOWLEDGEMENTS}

We would like to thank the authors for their contribution and support. We are grateful to all the participant that provided cervical swabs and answered the questionnaire.

\section{CONFLICT OF INTEREST}

All authors declare no conflict of interest.

\section{AUTHOR CONTRIBUTIONS}

SD conceived and designed the experiments. SD and DD performed the experiments. DD contributed materials. SD, KM and AC analysed the data. DPK contributed analysis tools. SD, DD and AC contributed to the writing of the manuscript.

\section{ETHICAL APPROVAL}

The study protocol was approved by the Ethics Committee of the Institute of Public Health of Republic of North Macedonia in accordance with the principles of the Helsinki Declaration, the national law and its latest amendments or comparable ethical standards.

\section{ORCID}

Sotirija Duvlis iD https://orcid.org/0000-0001-8587-7386

Aleksandar Cvetkovski iD https://orcid.org/0000-0002-8827-0245

Kristina Mladenovska iD https://orcid.org/0000-0003-2503-4699

Dijana Plaseska-Karanfilska iD https://orcid.

org/0000-0001-8877-2416

\section{REFERENCES}

Abraham, L. J., Grimsley, G., Leelayuwat, C., Townend, D. C., Pinelli, M., Christiansen, F. T., \& Dawkins, R. L. (1993). A region centromeric of the major histocompatibility complex class I region is as highly polymorphic as HLA-B. Implications for Recombination. Human Immunology, 38(1), 75-82.

Bazzoni, F., \& Beutler, B. (1996). The tumor necrosis factor ligand and receptor families. New England Journal of Medicine, 334(26), 1717-1725. https://doi.org/10.1056/nejm199606273342607

Bergeron, C., Barrasso, R., Beaudenon, S., Flamant, P., Croissant, O., \& Orth, G. (1992). Human papillomaviruses associated with cervical intraepithelial neoplasia. Great diversity and distinct distribution in low- and high-grade lesions. The American Journal of Surgical Pathology, 16(7), 641-649. https://doi.org/10.1097/00000478199207000-00002

Bernard, H. U., Chan, S. Y., Manos, M. M., Ong, C. K., Villa, L. L., Delius, H., ... Wheeler, C. M. (1994). Identification and assessment of known and novel human papillomaviruses by polymerase chain reaction amplification, restriction fragment length polymorphisms, nucleotide sequence, and phylogenetic algorithms. Journal of Infectious Diseases, 170(5), 1077-1085. https://doi.org/10.1093/infdis/170.5.1077

Beutler, B., \& Bazzoni, F. (1998). TNF, apoptosis and autoimmunity: A common thread? Blood Cells, Molecules, \& Diseases, 24(2), 216-230. https://doi.org/10.1006/bcmd.1998.0187

Calhoun, E. S., McGovern, R. M., Janney, C. A., Cerhan, J. R., Iturria, S. J., Smith, D. I., ... Persing, D. H. (2002). Host genetic polymorphism analysis in cervical cancer. Clinical Chemistry, 48(8), 1218-1224. https:// doi.org/10.1093/clinchem/48.8.1218

Chopra, V., Dinh, T. V., \& Hannigan, E. V. (1998). Circulating serum levels of cytokines and angiogenic factors in patients with cervical cancer. Cancer Investigation, 16(3), 152-159. https://doi.org/10.3109/07357 909809050029

Deshpande, A., Nolan, J. P., White, P. S., Valdez, Y. E., Hunt, W. C., Peyton, C. L., \& Wheeler, C. M. (2005). TNF-alpha promoter polymorphisms and susceptibility to human papillomavirus 16 -associated cervical cancer. Journal of Infectious Diseases, 191(6), 969-976. https://doi. org/10.1086/427826

Dranoff, G. (2004). Cytokines in cancer pathogenesis and cancer therapy. Nature Reviews Cancer, 4(1), 11-22. https://doi.org/10.1038/nrc1252

Duarte, I., Santos, A., Sousa, H., Catarino, R., Pinto, D., Matos, A., ... Medeiros, R. (2005). G-308A TNF-alpha polymorphism is associated with an increased risk of invasive cervical cancer. Biochemical and Biophysical Research Communications, 334(2), 588-592. https://doi. org/10.1016/j.bbrc.2005.06.137

Duvlis, S., Plaseska-Karanfilska, D., Bashevska, N., Dimitrov, G., Milanova, E., Naumov, J., \& Efremov, G. D. (2002). A variant of Human Papillomavirus type 66 is common among Macedonian women with cervical lesions. Balkan Journal of Medical Genetics, 4(4), 53-57.

Eskdale, J., Gallagher, G., Verweij, C. L., Keijsers, V., Westendorp, R. G., \& Huizinga, T. W. (1998). Interleukin 10 secretion in relation to human IL-10 locus haplotypes. Proceedings of National Academy of Sciences of the United States of America, 95(16), 9465-9470. https:// doi.org/10.1073/pnas.95.16.9465

Fong, C. L., Siddiqui, A. H., \& Mark, D. F. (1994). Identification and characterization of a novel repressor site in the human tumor necrosis factor alpha gene. Nucleic Acids Research, 22(6), 1108-1114. 
Gostout, B. S., Poland, G. A., Calhoun, E. S., Sohni, Y. R., Giuntoli II, R. L., McGovern, R. M., ... Persing, D. H. (2003). TAP1, TAP2, and HLA-DR2 alleles are predictors of cervical cancer risk. Gynecologic Oncology, 88(3), 326-332. https://doi.org/10.1016/S0090-8258(02)00074-4

Govan, V. A., Constant, D., Hoffman, M., \& Williamson, A. L. (2006). The allelic distribution of -308 Tumor Necrosis Factor-alpha gene polymorphism in South African women with cervical cancer and control women. BMC Cancer, 6, 24. https://doi.org/10.1186/1471-2407-6-24

Hajeer, A. H., \& Hutchinson, I. V. (2001). Influence of TNF-alpha gene polymorphisms on TNF-alpha production and disease. Human Immunology, 62(11), 1191-1199.

Ivansson, E. L., Magnusson, J. J., Magnusson, P. K., Erlich, H. A., \& Gyllensten, U. B. (2008). MHC loci affecting cervical cancer risk: Distinguishing the effects of HLA-DQB1 and non-HLA genes TNF, LTA, TAP1 and TAP2. Genes and Immunity, 9(7), 613-623. https://doi. org/10.1038/gene.2008.58

Jang, W. H., Yang, Y. I., Yea, S. S., Lee, Y. J., Chun, J. H., Kim, H. I., ... Paik, K. H. (2001). The -238 tumor necrosis factor-alpha promoter polymorphism is associated with decreased susceptibility to cancers. Cancer Letters, 166(1), 41-46.

Kirkpatrick, A., Bidwell, J., van den Brule, A. J., Meijer, C. J., Pawade, J., \& Glew, S. (2004). TNF-alpha polymorphism frequencies in HPVassociated cervical dysplasia. Gynecologic Oncology, 92(2), 675-679. https://doi.org/10.1016/j.ygyno.2003.11.025

Kohaar, I., Thakur, N., Salhan, S., Batra, S., Singh, V., Sharma, A., ... Bharadwaj, M. (2007). TNF-alpha-308G/A polymorphism as a risk factor for HPV associated cervical cancer in Indian population. Cellular Oncology, 29(3), 249-256.

Kroeger, K. M., Carville, K. S., \& Abraham, L. J. (1997). The -308 tumor necrosis factor-alpha promoter polymorphism effects transcription. Molecular Immunology, 34(5), 391-399.

Kyo, S., Inoue, M., Hayasaka, N., Inoue, T., Yutsudo, M., Tanizawa, O., \& Hakura, A. (1994). Regulation of early gene expression of human papillomavirus type 16 by inflammatory cytokines. Virology, 200(1), 130-139. https://doi.org/10.1006/viro.1994.1171

Li, L., Liu, J., Liu, C., \& Lu, X. (2018). The correlation between TNFalpha-308 gene polymorphism and susceptibility to cervical cancer. Oncol Lett, 15(5), 7163-7167. https://doi.org/10.3892/ol.2018.8246

Moore, K. W., O'Garra, A., de Waal Malefyt, R., Vieira, P., \& Mosmann, T. R. (1993). Interleukin-10. Annual Review of Immunology, 11, 165-190. https://doi.org/10.1146/annurev.iy.11.040193.001121

Noveski, P., Mircevska, M., Plaseski, T., Peterlin, B., \& Plaseska-Karanfilska, D. (2014). Study of Three Single Nucleotide Polymorphisms in the SLC6A14 Gene in Association with Male Infertility. Balkan Journal of Medical Genetics, 17(2), 61-66. https://doi.org/10.2478/ bjmg-2014-0075

Nunobiki, O., Ueda, M., Toji, E., Yamamoto, M., Akashi, K., Sato, N., ... Noda, S. (2011). Genetic polymorphism of cancer susceptibility genes and HPV infection in cervical carcinogenesis. Pathology Research International, 2011, 364069. https://doi.org/10.4061/2011/364069

Pan, F., Tian, J., Ji, C. S., He, Y. F., Han, X. H., Wang, Y., ... Hu, B. (2012). Association of TNF-alpha-308 and -238 polymorphisms with risk of cervical cancer: A meta-analysis. Asian Pacific Journal of Cancer Prevention, 13(11), 5777-5783.

Pavkovic, M., Petlichkovski, A., Angelovic, R., Genadieva-Stavric, S., Cevreska, L., \& Stojanovic, A. (2017). Tumor necrosis factor gene polymorphisms in adult patients with autoimmune hemolytic anemia. International Journal of Laboratory Hematology, 39(3), e74-e76. https://doi.org/10.1111/ijlh.12624

Roszak, A., Misztal, M., Sowinska, A., \& Jagodzinski, P. P. (2015). TNFalpha $-308 \mathrm{G} / \mathrm{A}$ as a risk marker of cervical cancer progression in the Polish population. Molecular Diagnosis and Therapy, 19(1), 53-57. https://doi.org/10.1007/s40291-015-0130-y

Singh, H., Jain, M., Sachan, R., \& Mittal, B. (2009). Association of TNF-A $(-308 \mathrm{G}>\mathrm{A})$ and IL-10 $(-819 \mathrm{C}>\mathrm{T})$ promoter polymorphisms with risk of cervical cancer. International Journal of Gynecological Cancer, 19(7), 1190-1194. https://doi.org/10.1111/IGC.0b013e3181a3a3af

Soto, U., Das, B. C., Lengert, M., Finzer, P., zur Hausen, H., \& Rosl, F. (1999). Conversion of HPV 18 positive non-tumorigenic HeLafibroblast hybrids to invasive growth involves loss of TNF-alpha mediated repression of viral transcription and modification of the AP-1 transcription complex. Oncogene, 18(21), 3187-3198. https://doi. org/10.1038/sj.onc.1202765

Stanczuk, G. A., Sibanda, E. N., Tswana, S. A., \& Bergstrom, S. (2003). Polymorphism at the -308 -promoter position of the tumor necrosis factor-alpha (TNF-alpha) gene and cervical cancer. International Journal of Gynecological Cancer, 13(2), 148-153. https://doi. org/10.1046/j.1525-1438.2003.13046.x

Trajkov, D., Mirkovska-Stojkovikj, J., Petlichkovski, A., Strezova, A., Efinska-Mladenovska, O., Sandevska, E., ... Spiroski, M. (2009). Association of cytokine gene polymorphisms with chronic obstructive pulmonary disease in Macedonians. Iranian Journal of Allergy Asthma and Immunology, 8(1), 31-42. 08.01/ijaai.3142

Ueda, M., Hung, Y.-C., Term, Y., Kanda, K., Takehara, M., Yamashita, H., ... Ueki, M. (2003). Glutathione S-transferase GSTM1, GSTT1 and p53 codon 72 polymorphisms in human tumor cells. Human Cell, 16(4), 241-251. https://doi.org/10.1111/j.1749-0774.2003.tb00158.x

Wang, Q., Zhang, C., Walayat, S., Chen, H. W., \& Wang, Y. (2011). Association between cytokine gene polymorphisms and cervical cancer in a Chinese population. European Journal of Obstetrics, Gynecology, and Reproductive Biology, 158(2), 330-333. https://doi. org/10.1016/j.ejogrb.2011.05.019

Wilson, A. G., Symons, J. A., McDowell, T. L., McDevitt, H. O., \& Duff, G. W. (1997). Effects of a polymorphism in the human tumor necrosis factor alpha promoter on transcriptional activation. Proceedings of National Academy of Sciences of the United States of America, 94(7), 3195-3199.

Zhou, P., Lv, G. Q., Wang, J. Z., Li, C. W., Du, L. F., Zhang, C., \& Li, J. P. (2011). The TNF-alpha-238 polymorphism and cancer risk: A meta-analysis. PLoS ONE, 6(7), e22092. https://doi.org/10.1371/journ al.pone.0022092

How to cite this article: Duvlis S, Dabeski D, Cvetkovski A, Mladenovska K, Plaseska-Karanfilska D. Association of TNF-a (rs361525 and rs1800629) with susceptibility to cervical intraepithelial lesion and cervical carcinoma in women from Republic of North Macedonia. Int J Immunogenet. 2020;00:17. https://doi.org/10.1111/iji.12506 